\title{
INFLUENCE OF HEAT TREATMENTS ON THE MICROSTRUCTURE AND TENSILE BEHAVIOUR OF SELECTIVE LASER MELTING-PRODUCED TI-6AL-4V PARTS
}

\author{
G.M. ter Haar ${ }^{1 *}$, T.H. Becker ${ }^{1} \&$ D.C. Blaine ${ }^{1}$
}

\section{ARTICLE INFO}

\begin{abstract}
Article details
Presented at the $17^{\text {th }}$ annual

international conference of the Rapid

Product Development Association of

South Africa (RAPDASA), held from 2-4

November 2016 in Vanderbijlpark, South Africa
\end{abstract}

Available online

11 Nov 2016

\section{Contact details \\ Corresponding author \\ gterhaar@sun.ac.za}

\section{Author affiliations}

1 Materials Engineering group,

Department of Mechanical \&

Mechatronic Engineering,

University of Stellenbosch, South Africa

DOI

http: / /dx.doi.org/10.7166/27-3-1663

\section{ABSTRACT}

In industry, post-process heat treatments of Ti-6Al-4V are performed with the aim of improving its tensile behaviour. While heat treatments of wrought Ti6Al4V have been standardised (e.g., Aerospace Material Specification $\mathrm{H}-81200$ ), heat treatments of selective laser melting (SLM)-produced Ti-6Al-4V lacks research and understanding. Significant concern exists about SLM Ti6-Al-4V's achievable ductility attributed to its martensitic ( $\left.a^{\prime}\right)$ phase. In this research, heat treatments at a range of temperatures are applied to SLM-produced Ti-6Al-4V tensile samples. Microstructural analysis (both optically and through electron backscatter diffraction) was used to identify links between heat treatments and microstructure. Subsequently, uniaxial tensile tests were performed to determine the respective tensile properties of all samples. Correlations in the data show a significant loss in strength with respect to an increase in annealing temperature due to grain growth, while no noticeable trend was observed for fracture strain with regard to annealing temperatures.

\section{OPSOMMING}

In die bedryf word hittebehandeling aangewend op Ti-6Al-4V met die doel om trek-eienskappe te verbeter. Alhoewel hittebehandeling van bewerkte Ti-6Al-4V gestandaardiseer is (bv. in Aerospace Material Specification H-81200), bestaan daar tekortkominge in die navorsing en begrip oor die hittebehandeling van selektiewe lasersmelting (SLM) vervaardigde Ti-6Al-4V. Hewige kommer bestaan oor SLM Ti-6Al-4V se bereikbare trekbaarheid weens die materiaal se martensitiese ( $a^{\prime}$ ) fase. In die studie is hittebehandeling by verskeie temperature aangewend op SLM vervaardigde trekmonsters. Mikrostruktuur analises (deur middel van opties asook elektron terugstrooiing diffraksie) is gebruik om koppels tussen hittebehandeling en mikrostruktuur te identifiseer. Gevolglik is trektoetse aangewend om die trekeienskappe van elke monster te bepaal. Ooreenstemming in data toon 'n noemenswaardige verlies van sterkte met ' $n$ verhoging van hittebehandelingtemperatuur weens ' $n$ groei in kristalgrote, terwyl geen kenmerkende tendens tussen trekvervorming-by-breek met betrekking tot hittebehandeling temperatuur gewaar is nie.

\section{INTRODUCTION}

The industry of additive manufacturing (AM) has grown exponentially since 2006 . This growth can be attributed, among others factors, to the development and improvement of the technology and thereby the improvement of the achievable quality of manufactured parts. A popular $A M$ technique used for the manufacturing of metallic parts for application in the biomedical and aerospace industries is selective laser melting (SLM) - a metal additive manufacturing (MAM) technique that has advantages in a wide range of applicable areas. Besides SLM's ability to form shapes that are not possible through the use of traditional techniques, and its shorter lead time, it allows for minimal 
material waste and therefore more environmentally-sustainable manufacturing techniques [1]. The application of SLM-produced Ti-6Al-4V ELI (Extra Low Interstitials) is becoming increasingly predominant in the fields of biomedical and aerospace industries [2] due to its excellent mechanical properties and the aforementioned advantages that MAM offers.

However, there is significant concern in the literature about SLM-produced Ti-6Al-4V's achievable mechanical properties [2]. Part ductility (percentage elongation-to-break) is of particular concern, since research has found the elongation-to-break (fracture strain) to be below the 10 per cent American Standard Test Method (ASTM) limit [3] (ASTM F2924-14) to qualify for use in biomedical [4] and aerospace industries (Aerospace Material Standard (AMS) 4911). It is well-established that mechanical properties depend on microstructure [5]. However, the microstructure of SLM Ti-6Al-4V depends on a wide range of factors, including material (powder) properties, process parameters, scanning strategy, and part geometry. Controlling the mechanical and material properties of SLMproduced Ti-6Al-4V is not as well-established as standard methods such as wrought and cast parts, and therefore it requires research and development.

Industrial post-process heat treatments, which are typically used to alter Ti-6Al-4V microstructure in order to increase its tensile performance (strength, toughness, and ductility), do not necessarily apply to SLM Ti-6Al-4V. The starting microstructure of SLM Ti-6Al-4V is significantly different from that of its wrought counterpart. Microstructure formed through the fast cooling of laser melting in SLM is needle-like metastable martensite ( $\left.\alpha^{\prime}\right)$, while wrought Ti-6Al-4V is typically a stable equiaxed or bi-modal microstructure. As such, ductility values of post-heat-treated SLM Ti-6Al-4V have been reported in the range of 8 and 10 per cent $[7,8]$ and up to 12 per cent [8]. This is less than its wrought counterpart (16-18 per cent elongation at break [5]) and below the requirements set by some standards (ASTM F1472-08). Investigation into various tailored heat treatments have been done by various authors [8,11, 12]; however, a consistently lower ductility has been reported so far [6].

Functional Ti-6Al-4V parts manufactured through SLM have only recently been successfully introduced into industry. However, the lack in material ductility (elongation strain to fracture) of these parts is a major setback or disadvantage of the manufacturing process. Through determining the tensile properties of SLM Ti-6Al-4V samples that have been heat-treated at various temperatures, correlations between tensile behaviour and annealing temperature can be identified. The aim of this research is to contribute to the limited understanding of the link between SLM Ti$6 \mathrm{Al}-4 \mathrm{~V}$ microstructure and heat treatments at various temperatures, as well as the achievable tensile properties of these 'typical' SLM Ti-6Al-4V heat treatments.

\section{EXPERIMENTAL METHODS}

The experimental methodology aimed to determine the tensile properties of a wide range of heat treatments using SLM-produced Ti-6Al-4V samples. Microstructural analysis through optical and electron backscatter diffraction (EBSD) enabled the identification of crystallographic features that influence the tensile behaviour of the material.

\subsection{Tensile samples}

Cylindrical samples with a diameter of $15 \mathrm{~mm}$ and a length of $93 \mathrm{~mm}$ were designed using computeraided design (CAD), sliced into layers using the software Magics, and produced using a LaserCusing M2 machine from Concept Laser. The samples were built vertically - i.e., the build direction was in the Z-direction (in terms of ASTM F2924-14 orientation convention) in a continuous flow of argon gas ( $45 \mathrm{l} / \mathrm{min})$. Default process parameters recommended for Concept Laser's Ti-6Al-4V (ELI) powder were used. These parameters are shown in Table 1.

\section{Table 1: Parameters of the printing process}

\begin{tabular}{|l|l|l|l|l|l|}
\hline $\begin{array}{l}\text { Power }(\mathrm{P}) \\
{[\mathrm{W}]}\end{array}$ & $\begin{array}{l}\text { Velocity }(\mathrm{v}) \\
{[\mathrm{mm} / \mathrm{s}]}\end{array}$ & $\begin{array}{l}\text { Layer thickness } \\
{[\mu \mathrm{m}]}\end{array}$ & $\begin{array}{l}\text { Laser spot diameter } \\
{[\mu \mathrm{m}]}\end{array}$ & $\begin{array}{l}\text { Hatch spacing } \\
{[\mu \mathrm{m}]}\end{array}$ & $\begin{array}{l}\text { Beam compensation } \\
{[\mu \mathrm{m}]}\end{array}$ \\
\hline 100 & 600 & 30 & 150 & 105 & 22.5 \\
\hline
\end{tabular}

The $M 2$ machine by default builds using an 'island' scan strategy. This strategy scans the surface in $5 \mathrm{~mm}$-sized squares. These squares are at $45^{\circ}$ to the baseplate $X$-axis and are each scanned in a 'zigzag' pattern, with each adjacent square being scanned at $90^{\circ}$ relative to its neighbours, as shown 
in Error! Reference source not found.. Consecutive layers are shifted $1 \mathrm{~mm}$ in the XY plane away from the previously scanned square and scanned at $90^{\circ}$ to the previous layer. The part perimeter of each layer is scanned last, using the same laser setting, to improve the surface quality of the finished part.

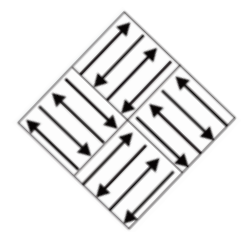

Figure 1: Hatch strategy [9]

Pre-alloyed Ti-6Al-4V (ELI) powder from TLS Technik GmbH \& Co was used. The powder particle's size is reported by the manufacturer to be $25-55 \mu \mathrm{m}$ in diameter. All samples were built from fresh powder that had not yet been recycled. Elemental analysis of the powder was done at the South African Nuclear Energy Corporation's Pelindaba Analytical Labs. Inductively-coupled plasma optical emission spectrometry (ICP-OES) of the powder was used to identify the weight percentages of the metallic elements, while an inert gas fusion technique was used to identify the gas elements. The average elemental composition results of two powder canisters are shown in Table 2.

Table 2: Elemental composition of powder

\begin{tabular}{|l|l|l|}
\hline Determination & Result & Units \\
\hline Aluminium $(\mathrm{Al})$ & 6.06 & $\%$ \\
\hline Iron $(\mathrm{Fe})$ & 0.16 & $\%$ \\
\hline Titanium $(\mathrm{Ti})$ & 89.9 & $\%$ \\
\hline Vanadium $(\mathrm{V})$ & 3.82 & $\%$ \\
\hline Oxygen $\left(\mathrm{O}_{2}\right)$ & 786.5 & $\mathrm{mg} / \mathrm{kg}(\mathrm{ppm})$ \\
\hline Nitrogen $\left(\mathrm{N}_{2}\right)$ & 89.5 & $\mathrm{mg} / \mathrm{kg}(\mathrm{ppm})$ \\
\hline
\end{tabular}

\subsection{Heat treatments}

An electrical muffle furnace from Gallenkamp was used for all heat treatments, as its large volumetric capacity allowed a large group of samples to be heat-treated simultaneously. Whereas the preferred furnace used for titanium and its alloys is a vacuum furnace (due to the material's high affinity to reacting with oxygen), the post-machining of the samples allowed for a complete removal of contaminated material (such as a-case). Five samples from the same build were selected semi-randomly to form a heat treatment batch/group. Although randomly picked, batches were carefully selected to represent (as far as possible) all areas of the build plate (back, front, middle, etc.). Batches were placed in the centre (between the floor and the roof) of the furnace (on a brick) equally spaced $3 \mathrm{~cm}$ apart (back of furnace to the front).

Studies to date have suggested that annealing below the B-transus (reported as $975^{\circ} \mathrm{C}$ by Lütjering and Williams [10]) of SLM Ti-6Al-4V provides the optimal ratio of strength and ductility [7, 15-17]. This is due to the phenomenon of martensitic ( $\left.\alpha^{\prime}\right)$ decomposition into $(\alpha+B)$ phase microstructure and the subsequent tensile behaviour of the $(a+B)$ phase microstructure. According to the literature, it is key to this typical type of SLM heat treatment that the strength of the fine microstructure of the transformed martensite is preserved while ductility is improved due to $(\alpha+B)$. While optically a' grains and a grains are indistinguishable other than by their difference in size, the two phases are fundamentally different due to their respective elemental composition and therefore their tensile behaviour.

The type and range of annealing temperatures investigated in this research not only coincides with the typical heat treatment of SLM Ti-6Al-4V investigated in research, but also the industrial standard 'over-aging' heat treatment of wrought Ti-6Al-4V, as reported by Donachie [5]. Over-aging entails heat-treating a water-quenched Ti-6Al-4V wrought sample at a high sub- $\mathrm{B}$-transus temperature (705$760^{\circ} \mathrm{C}$ ) to decompose the water-quenched a' phase into secondary a phase, thereby creating the desired bi-modal microstructure. Since only one annealing step is investigated in this research, and since the starting microstructure is a' rather than the primary a of wrought Ti-6Al-4V, a bi-modal microstructure is not achieved. Ultimately, the chosen sub- $B$-transus heat treatments are designed to increase ductility by transforming the less-ductile $\alpha^{\prime}$ phase into a $(\alpha+B)$ phase microstructure. 
Heat treatments were chosen in order to obtain a broad set of sub-B-transus temperature data. Temperature regions of $700^{\circ} \mathrm{C}, 770^{\circ} \mathrm{C}$, and $800^{\circ} \mathrm{C}$ were chosen as heat treatments below the $\mathrm{B}$ transus. A super- $B$-transus heat treatment (heating above the $B$-transus, also called full anneal) was also done for comparative purposes. The hold time at temperature was chosen as four hours for an annealing temperature region of $800^{\circ} \mathrm{C}$, which was based on literature findings that showed a complete martensitic decomposition at $800^{\circ} \mathrm{C}$ for this holding time [11]. Holding time for samples annealed at $700^{\circ} \mathrm{C}$ and $770^{\circ} \mathrm{C}(\mathrm{FG})$ were chosen as eight hours, based on the assumption that the martensite would decompose after this amount of time. Eight hours also coincides with the length of time recommended by the Aeronautical Materials Standard for heat treatments of titanium and titanium alloys (AMS H81200).

The cooling method/rate for all sub- $B$-transus heat treatments was based on literature findings that showed the Vanadium weight percentage in the $B$ phase, at this temperature range, to stabilise the $B$ phase sufficiently and thereby prevent nucleation and growth of new $a / a$ ' phase upon cooling [12]. Air cooling of Ti-6Al-4V is considered an intermediate cooling rate and approximated to be $\sim 10^{\circ} \mathrm{C} / \mathrm{s}$ [13]. Furnace cooling from above $B$-transus (leaving samples in the furnace once it has been switched off) was chosen specifically to achieve a 'colony' microstructure, and was measured to be approximately $3-5^{\circ} \mathrm{C} / \mathrm{min}$ at $800^{\circ} \mathrm{C}$.

The temperature profile of the furnace at high temperature was measured, showing that there is a gradual temperature gradient from the furnace back-wall to the furnace door. In order to determine the temperature of each sample in the furnace accurately, a thermal profile model of the furnace was generated by measuring the temperature in the centre of the furnace, in $2 \mathrm{~cm}$ intervals, from the back to the front of the furnace. Since the furnace gauge temperature of each batch and the position of each sample are known, each individual sample's temperature could be determined. The outline/summary of the executed heat treatments is shown in Table 3 . Since the measured temperature drops sharply close to the door, samples that were placed in the centre of the furnace were chosen for microstructural evaluation, as they represented a typical part.

Table 3: Outline of heat treatments

\begin{tabular}{|c|c|c|c|}
\hline Furnace gauge temperature $\left[{ }^{\circ} \mathrm{C}\right.$ ] & Sample temperatures $\left[{ }^{\circ} \mathrm{C}\right.$ ] & Holding time [hours] & Cooling method \\
\hline 700 & $740,735,728,720,708$ & 8 & Air \\
\hline 770 & $810,805,798,790,778$ & 8 & Air \\
\hline 800 & $840,835,828,820,808$ & 4 & Air \\
\hline 1000 & $1040,1035,1028,1020,1008$ & 4 & Furnace \\
\hline
\end{tabular}

\subsection{Tensile tests}

Once heat treatments had been carried out, samples were machined into cylindrical dog-boneshaped specimens in accordance with ASTM E8M-15. Sample gauge diameter (D) was machined to be $5 \mathrm{~mm}$ with a gauge length of 5D. Tests were done using an MTS Criterion Model 44 with a $30 \mathrm{kN}$ load cell. A low crosshead rate of $0.35 \mathrm{~mm} / \mathrm{min}$ was used, as suggested by ASTM E8/E8M-11. Data collected from the tensile tests is load, crosshead displacement, and extensometer displacement. From this data, ultimate tensile strength (UTS), 0.2 per cent offset yield stress, Young's Modulus, and elongation at failure were determined.

To determine Young's Modulus, an MFA extensometer, which satisfies the EN ISO 9513 accuracy class 0.5 and which has a $25.4 \mathrm{~mm}$ gauge length, was used. Failure strain was determined from crosshead displacement. Tensile test result data was processed in Excel and Matlab.

\subsection{Microstructural characterisation}

A centre sample from each annealed batch was chosen to represent a typical part annealed in the muffle furnace. A single cylindrical end-offcut $10 \mathrm{~mm}$ long was cut along the XY plane. The offcut was also cut perpendicular to its XY plane to reveal the ZX plane. The offcuts were mounted in resin, ground with a 1000 grid SiC paper, and then polished with $9 \mu \mathrm{m}$ DiaPro Allegro/Largo suspension liquid ( $30 \mathrm{~N}$ load) for five minutes, and a $0.04 \mu \mathrm{m}$ OP-S solution ( $30 \mathrm{~N}$ load) for five minutes. The surface was then etched using Kroll's reagent to reveal the microstructure. Microstructure was observed using an Olympus GX51 optical microscope. Selected samples were scanned at Nelson Mandela Metropolitan University (NMMU). The microstructure of the XY and ZX planes were scanned using the SEM setting shown in Table 4. 
Table 4: SEM acquisition setting

\begin{tabular}{|l|l|}
\hline Accelerating voltage & $15.00 \mathrm{kV}$ \\
\hline Specimen tilt & $70.05^{\circ}$ \\
\hline Hit rate & $99.60 \%$ \\
\hline Speed of acquisition & $40.52 \mathrm{~Hz}$ \\
\hline Step size & $0.5 \mu \mathrm{m}$ \\
\hline Magnification & $300 \mathrm{x}$ \\
\hline Scan size & $0.7 \mathrm{~mm}$ square \\
\hline
\end{tabular}

Crystallographic lattice data was automatically transformed (Hough transform) and indexed using the HKL data base. EBSD scan data was analysed in Matlab using the open source toolbox MTEX (version 4.4.alpha.5).

Crystallographic orientation data obtained from EBSD allows for a greater wealth of information to be attained for analysis. Prior- $B$ grains boundaries (and orientation) can be determined from using the a grain orientation data in conjunction with Burger's Orientation Relationship (BOR), as demonstrated by Wang et al. [14]. BOR is a fixed-orientation relationship between the hightemperature $B$ phase orientation and the low-temperature a phase orientation. Ultimately, it follows that only twelve a grain orientations are capable of forming from a single $B$ orientation (i.e. $B$ grain). With the aid of BOR knowledge, prior-B-phase information can be calculated and analysed from a phase orientation information.

\section{RESULTS}

The results of microstructure obtained through optical and EBSD maps are presented first. A comparison is made between the effects of different heat treatments on microstructural features. Plots of uniaxial tensile tests results are then presented and discussed.

\subsection{Optical microscopy - grain size}

Figure 2 compares the micrographs of etched off-cuts of (a) a sample annealed at $828^{\circ} \mathrm{C}$ and (b) a sample annealed at $878^{\circ} \mathrm{C}$. The increase in grain size from (a) to (b) can be clearly seen. The broadening of $B$ phase (dark regions) is also noticeable.

(a)

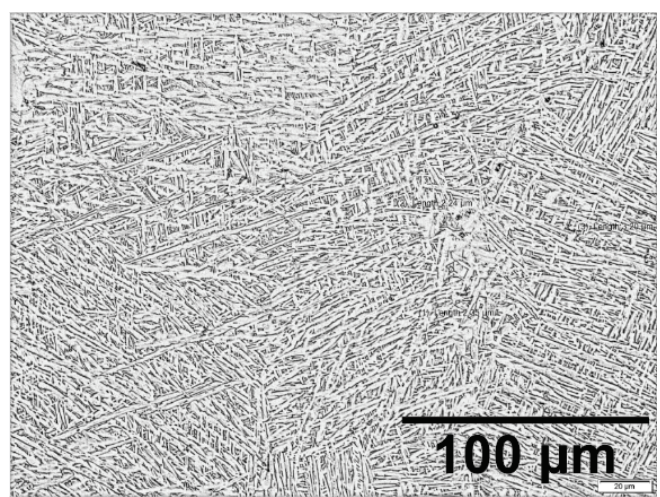

(b)

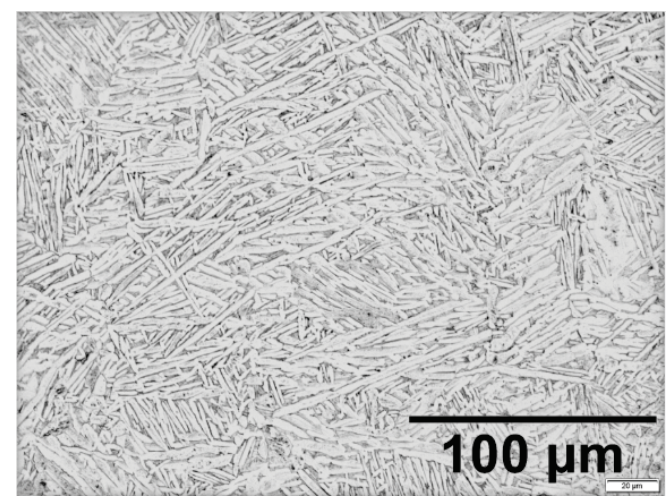

Figure 2: Decomposition into dual-phase $(a+B)$ and increase in a grain from (a) $828^{\circ} \mathrm{C}$ to (b) $878^{\circ} \mathrm{C}$

The average grain size of the two samples in Figure 2 was measured using an automated line intercept method in Matlab. The average grain size of the samples annealed at $828^{\circ} \mathrm{C}$ and $878^{\circ} \mathrm{C}$ is 1.57 and $2.94 \mu \mathrm{m}$ respectively. These results coincide with those of Xu et al. [15]

\subsection{Electron backscatter diffraction - prior-B grain size}

Figure 3 depicts inverse pole HSV (hue, saturation, value) orientation maps of the as-built sample off-cut in the (a) XY- and (b) ZX-planes. The orientation colour key can be referred to in Figure 3(d). Thin black lines were plotted on a grain boundary whose misorientation can only exist at prior- $B$ grain boundaries (due to the aforementioned BOR). The black lines therefore represent prior- $B$ grain boundaries. It is clear from the XY plane in Figure 3(a) that the unique B grain shape forms due to 
the alternating 'zigzag' scanning strategy (emphasised by the parallel broken lines). The $B$ grain size furthermore corresponds to the laser spot size. In Figure 3(b), the ZX plane depicts the columnarshaped prior- $B$ grain structure commonly observed in SLM-produced samples. The prior- $B$ grain shape formed due to epitaxial growth of the $B$-phase during processing is unique to MAM, due to the nature of the building process. Prior- $B$ grain shape has been shown to cause anisotropy of tensile behaviour [16]. Heat treatments below the $B$-transus were found to have no influence on prior- $B$ grain size or shape.

(a)

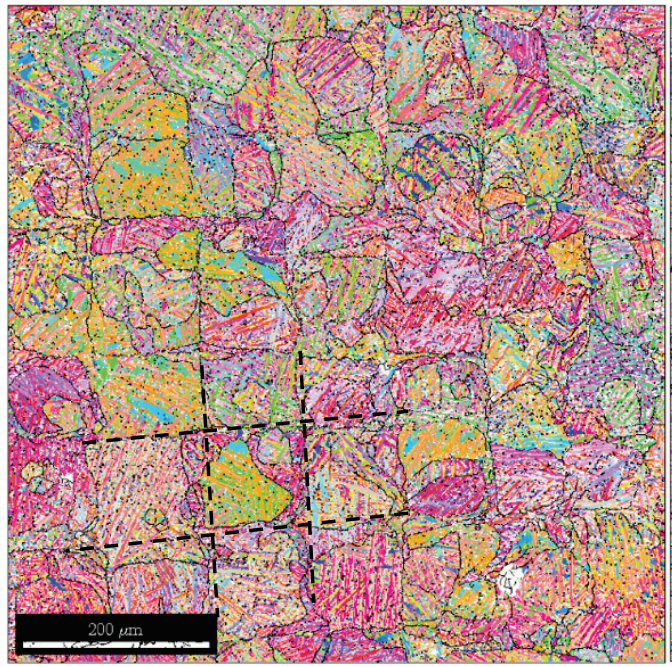

(c)

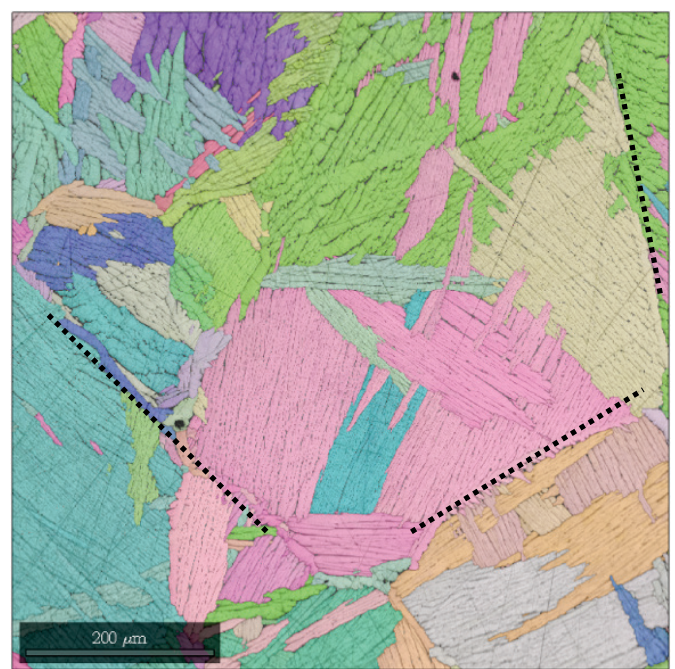

(b)

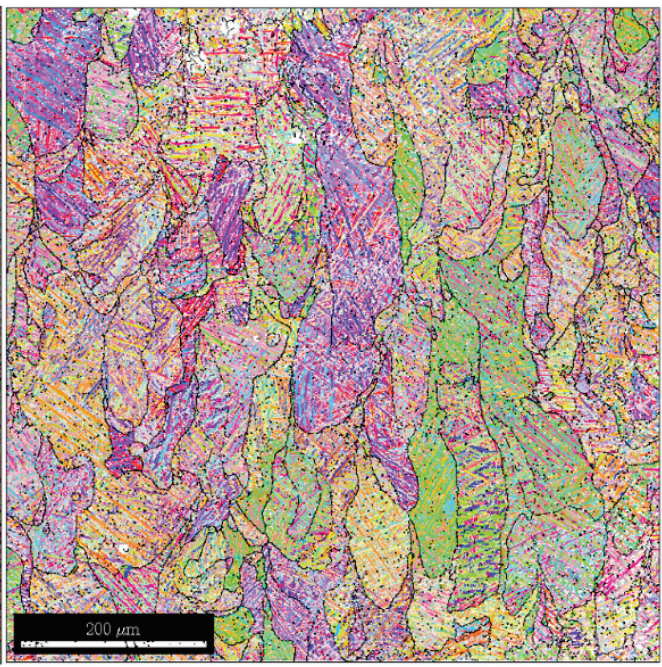

(d)

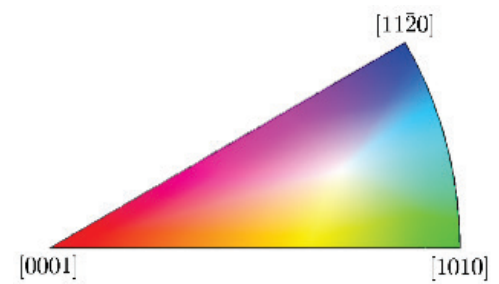

Figure 3: (a) as-built (non-heat treated) sample: a phase orientation map. XY plane; (b) ZX plane; (c) furnace cooled from above the $B$-transus: broken lines indicated prior- $B$ grain boundaries; and (d) inverse pole HSV orientation colour key.

When Ti-6Al-4V is annealed above its B-transus temperature, B-phase grain growth is achieved. A strong juxtaposition of grain morphology can be observed when comparing the orientation map of the fully annealed sample depicted in Figure 3(c) with that of the as-built sample (and sub-B-transus microstructure). Note that both maps are at identical magnification. The fully-annealed sample's a grains are packed in colonies of parallel grains. A prior-B grain, outlined by broken lines in Figure 3 (c), has grown greatly from its initial as-built size. An important metallographic characteristic of these colonies is that all the a grains in a colony are the same orientation. This has the effect that a single colony, to an extent, acts as a single grain and therefore as a single slip system. This phenomenon can be seen by slip lines on the surface of the sample, discussed in the next section. 


\subsection{Slip systems}

Slip lines on the gauge length of sample surfaces were observed. Figure 4 depicts samples with their $\mathrm{Z}$-axis pointing north with reference to the page. Slip lines and bulk plastic deformation on the full annealed sample are abundant, while in the sub- $B$-transus group, such as samples heat-treated at $828^{\circ} \mathrm{C}$ (Figure 4(b)), the slip line groups are sporadic and shorter in length. The difference in size of slip groups coincides with the microstructural size of the respective samples, as discussed in the previous section. The difference in plastic behaviour of the two groups can therefore be shown to be a function of both prior- $B$ grain size and a grain morphology.

(a)

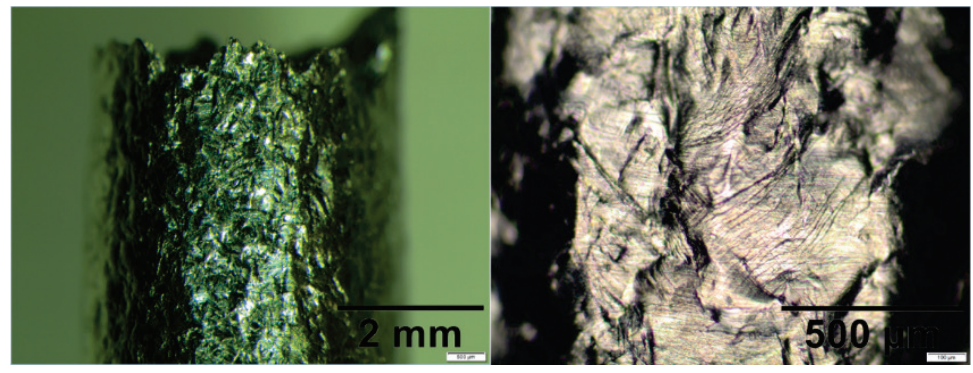

(b)

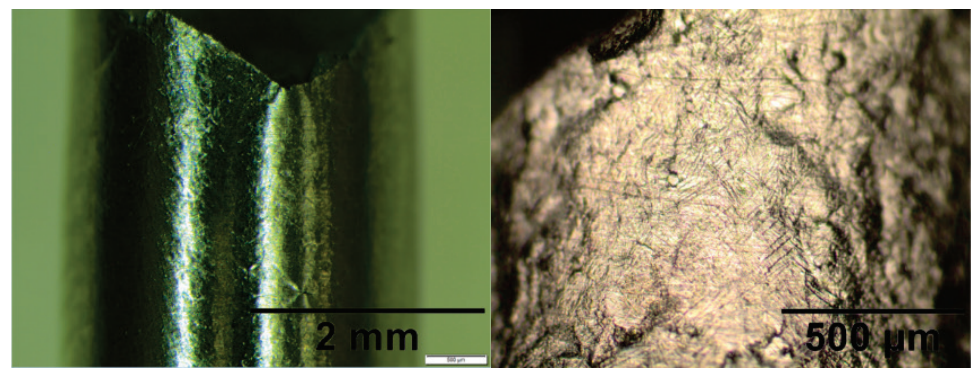

Figure 4: Plastic surface deformation: (a) fully annealed sample $\left(1028^{\circ} \mathrm{C}\right)$; (b) sub-B transus heat-treated sample $\left(828^{\circ} \mathrm{C}\right)$

\subsection{Tensile tests}

Results of the tensile tests were plotted to determined trends in correlation between tensile properties and microstructure. A plot of material strength (UTS and Yield) versus failure strain, as shown in Figure $5(\mathrm{a}-\mathrm{c})$, reveals a correlation between strength and ductility. A power-law trend line is fitted to the data. It is worth noting the overlap in failure strain values between the heat-treated samples and the as-built samples. This is noteworthy, since the original goal of the heat treatments was to increase ductility; however, some of the heat treatments appear not to have achieved this purpose. The sample strengths vs temperature is plotted in Figure 5(d). A linear trend in data can be observed. The decrease in strength is attributed to grain growth, since an inverse square root relationship exists between grain size and yield strength (Hall-Patch Relationship), and grain size is increased with temperature (as discussed in Section 3.1).

Lastly, plots of failure strain vs annealing temperature for the sub-B-transus group (Figure 6(a)) and the super-B-transus group (Figure 6(b)) are plotted. No clear trend can be distinguished in the sub$B$-transus group, while a linear trend appears to exist for the super- $B$-transus group. This linear trend in data can be explained by the growth of the $B$ grain size above the $B$ transus temperature. Since lamella colony size is a function of $B$ grain size, a larger $B$ grain size results in a larger colony size. Lütjering [17] has shown that elongation to failure decreases with an increase in lamella colony size.

Although an improvement of ductility at a higher sub-B-transus annealing temperature was shown, the data suggests no further improvement in ductility for temperatures above those investigated in this paper. On the contrary, the trend in strength with temperature suggests that material strength will only further decrease, therefore making annealing at higher temperatures unfavourable. 
(d)
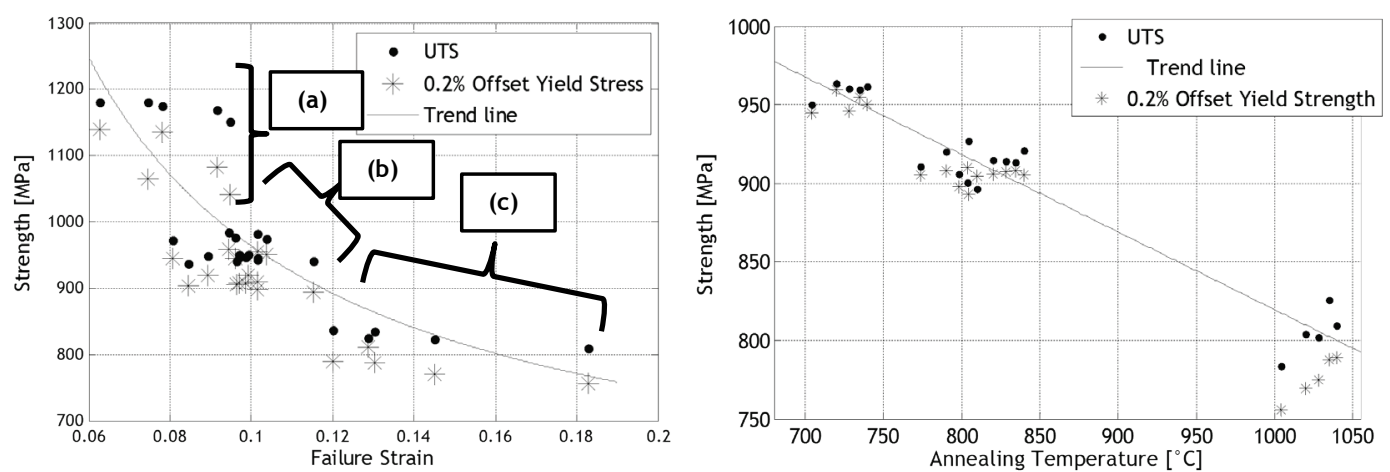

Figure 5: Plot of strength vs failure strain: (a) as-built; (b) sub-B-transus anneal; (c) full anneal; and (d) plot of material strength vs annealing temperature

(a)

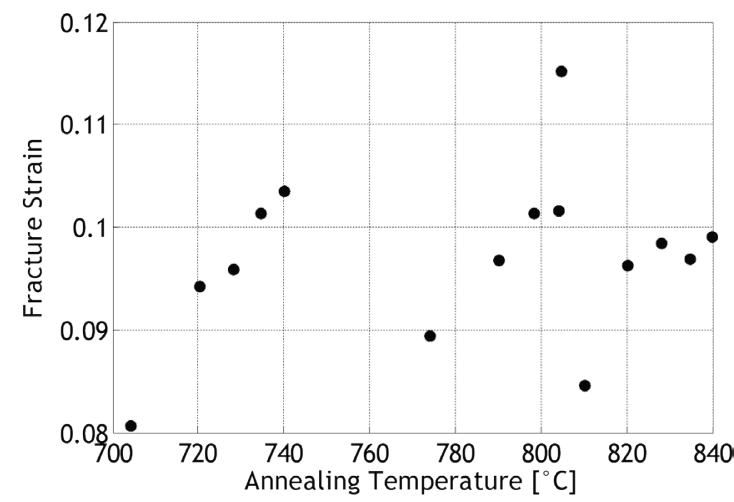

(b)

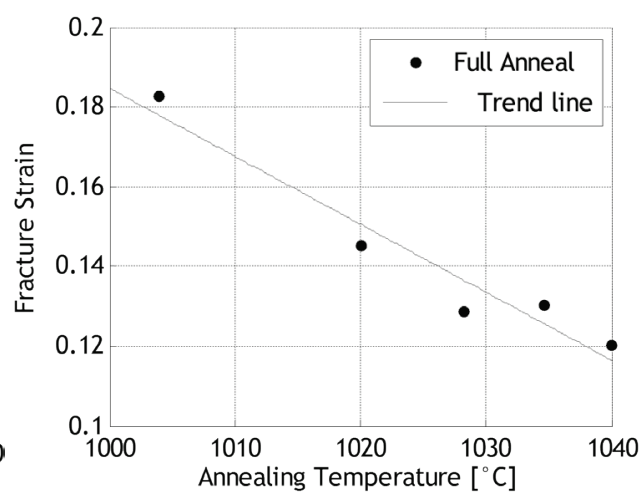

Figure 6: Fracture strain vs annealing temperature for (a) sub-B-transus annealing; and (b) super-B-transus annealing

\subsection{Young's Modulus}

Since no correlation between annealing temperature and material stiffness was observed, the mean and median Young's Moduli were grouped as follows: as-built, sub- $B$ annealed, and super- $B$ annealed (Table 5). Young's Moduli of Ti-6Al-4V phases are compared in magnitude by $\alpha>\alpha^{\prime}>B$. In the literature, individual Young's Moduli of $a, a^{\prime}$, and $B$ are calculated to be 117, 114, and 82 GPa respectively [18].

Table 5: Young's modulus of annealing group

\begin{tabular}{|c|c|c|}
\hline Group & $\mathrm{E}_{\text {avg }}-$ mean [GPa] & $\mathrm{E}_{\text {avg }}-$ median [GPa] \\
\hline As-built & 116.16 & 114.79 \\
\hline Sub-B-transus & 119.12 & 114.65 \\
\hline Full anneal & 114.34 & 105.56 \\
\hline
\end{tabular}

Martensitic decomposition causes the simultaneous formation of $a$ and $B$, which in turn causes the elastic stiffness to both increase and decrease; an increase is due to the formation of the a phase and a decrease is due to the formation of the $B$ phase. The increase in magnitude of measured Young's Moduli in the sub- $B$ transus group points to the effect that the $a^{\prime} \rightarrow$ a prevailed over the $a^{\prime} \rightarrow$ $B$ transformation (also noted by Sallica-Leva et al. [19]). In the fully annealed sample, the opposite is true; since the mean and median of the Young's modulus decreases from the as-built to the full annealed sample, it follows that the $\alpha^{\prime} \rightarrow B$ prevailed over the $\alpha^{\prime} \rightarrow a$ transformation. It can therefore be argued that the $B$ phase percentage in the full annealed sample is greater. Furthermore, the lower stiffness contributes to the greater ductility, as demonstrated by the tensile results. 
Research has been carried out that was aimed at identifying a correlation between SLM-produced $\mathrm{Ti}-6 \mathrm{Al}-4 \mathrm{~V}$ tensile properties and microstructure for a range of annealing temperatures. Microstructural analysis through optical micrographs and EBSD scans allowed for insight into the microstructural kinematics with respect to annealing temperature. Tensile tests of annealed samples were undertaken to obtain strength, stiffness, and ductility data. Correlating tensile data, microstructure, and annealing temperatures allowed for data trends to be revealed.

Sub- $B$-transus heat treatments served to decompose the $a$ ' phase into a fine dual-phase microstructure identified by the original fine structure of the as-built martensite, transformed, however, into a thicker, duel phase $(a+B)$ microstructure. Higher temperature sub- $B$-transus heat treatments caused a larger percentage of recrystallisation of the $\alpha$ ' grains. This caused the enlargement (thickening) of a grains and therefore a decrease in strength.

A comparison of plastic slip on the surface of sub- $B$-transus and super- $B$-transus samples revealed the latter to have much larger plastic slip lines. This is attributed to the growth in beta grains and the formation of a colony structure of the newly-formed a grains (observed in Figure 3(c)). This microstructural morphology significantly reduces the strength of the material while increasing its ductility. The strength of the samples in the fully annealed group falls below that required by ASTM F2921-08, thus making this heat treatment unfavourable.

The measured stiffness of the three groups of samples (as-built, sub- $B$-transus, and full anneal) gave insight into the extent and influence of the heat treatment on preferential formation of $a$ or $B$ from $a^{\prime}$. An increase in stiffness was revealed for sub- $B$-transus-treated samples, which suggests a preferential formation of a phase over $B$ phase. For the full annealed group, however, the median stiffness was decreased, which suggests a preferential transformation to $B$ phase.

Although ductility was improved by the majority of sub- $B$-transus heat treatments, it was at the cost of a substantial loss in material strength (15-20 per cent) due to a phase grain growth. Furthermore, no correlation between annealing temperature and fracture strain in the sub- $B$-transus region was observed. The results therefore point to a low sub- $B$-transus heat treatment as the optimal heat treatment temperature.

\section{ACKNOWLEDGEMENTS}

The authors acknowledge funding by the Department of Science and Technology through the Collaborative Programme in Additive Manufacturing (CPAM). The authors also acknowledge the following individuals: Mr Adonis from Cape Metrology for carrying out the furnace calibration, $\mathrm{Mr}$ Goosen and Dr Westraadt for lengthy EBSD scanning, and J. L. Mokgawa, S. Sibiya, D.C. HudsonLamb, and W.G. van Niekerk for the powder elemental analysis.

\section{REFERENCES}

[1] Baumers, M., Tuck, C., Hague, R., Ashcroft, I. and Wildman, R. 2010. A comparative study of metallic additive manufacturing power consumption. Solid Freeform Fabrication Symposium, pp. 278-288.

[2] Becker, T. 2014. Proposal to the DST - Qualification of Additive Manufacturing of Ti6Al4V for Medical Implants and Aerospace, Stellenbosch.

[3] Hollander, D. A., Von Walter, M., Wirtz, T., Sellei, R., Schmidt-Rohlfing, B., Paar, O. and Erli, H.J. 2006. Structural, mechanical and in vitro characterization of individually structured Ti-6Al-4V produced by direct laser forming. Biomaterials, 27(7), pp. 955-963.

[4] Yadroitsev, I., Krakhmalev, P. and Yadroitsava, I. 2014. Selective laser melting of Ti6Al4V alloy for biomedical applications: Temperature monitoring and microstructural evolution. Journal of Alloys and Compounds, 583, pp. 404-409.

[5] Donachie, M. 2000. Titanium A Technical Guide, Ohio.

[6] Xu, W., Brandt, M., Sun, S., Elambasseril, J., Liu, Q., Latham, K., Xia, K. and Qian, M. 2015. Additive manufacturing of strong and ductile Ti-6Al-4V by selective laser melting via in situ martensite decomposition. Acta Materialia, 85(November), pp. 74-84.

[7] Vrancken, B., Thijs, L., Kruth, J.-P. and Van Humbeeck, J. 2012. Heat treatment of Ti6Al4V produced by Selective Laser Melting: Microstructure and mechanical properties. Journal of Alloys and Compounds, 541(0), pp. 177-185.

[8] Kahn, R. 2014. Microstructural Investigation of Selective Laser Melted Ti6Al4V, Stellenbsoch University. 
[9] Thijs, L. 2014. Microstructure and texture of metal parts produced by Selective Laser Melting, KU Leuven.

[10] Luitjering, G. and Williams, J. C. 2007. Titanium, Springer Berlin Heidelberg, Berlin, Heidelberg.

[11] Huang, Q., Liu, X., Yang, X., Zhang, R., Shen, Z. and Feng, Q. 2015. Specific heat treatment of selective laser melted Ti-6Al-4V for biomedical applications. Frontiers of Materials Science, 9(4), pp. 373-381.

[12] Sha, W. and Malinov, S. 2009. Titanium alloys: modelling of microstructure, properties and applications, CRC Press.

[13] Kelly, S. M. 2004. Thermal and Microstructure Modeling of Metal Deposition Processes with Application to Ti-6Al-4V, State University.

[14] Wang, S. C., Starink, M. J., Ubhi, H. S. and Li, W. S. 2012. Identification of transformed grain boundaries and reconstruction of the prior grains from EBSD data in pure $\mathrm{Ti}$ and a-Ti alloys. Reviews on Advanced Materials Science, 32(1), pp. 47-51.

[15] Xu, W., Sun, S., Elambasseril, J., Liu, Q., Brandt, M. and Qian, M. 2015. Ti-6Al-4V Additively Manufactured by Selective Laser Melting with Superior Mechanical Properties. The Journal of The Minerals, Metals \& Materials Society (TMS), 67(3), pp. 1-6.

[16] Carroll, B. E., Palmer, T. A.. and Beese, A. M. 2015. Anisotropic tensile behavior of Ti-6Al-4V components fabricated with directed energy deposition additive manufacturing. Acta Materialia, 87, pp. 309-320.

[17] Luitjering, G. 1998. Influence of processing on microstructure and mechanical properties of $(\alpha+B)$ titanium alloys. Materials Science and Engineering: A, 243(1-2), pp. 32-45.

[18] Crespo, A. 2011. Modelling of Heat Transfer and Phase Transformations in the Rapid Manufacturing of Titanium Components, Convection and Conduction Heat Transfer. InTech, pp. 315-340.

[19] Sallica-Leva, E., Caram, R., Jardini, A. L. and Fogagnolo, J. B. 2016. Ductility improvement due to martensite a' decomposition in porous Ti-6Al-4V parts produced by selective laser melting for orthopedic implants. Journal of the Mechanical Behavior of Biomedical Materials, 54, pp. 149-158. 